\title{
Molecular Characterization of Cytidine Monophospho-N-Acetylneuraminic Acid Hydroxylase (CMAH) Gene and Frequency of Blood Types in Stray Cats of İzmir, Turkey
}

\author{
Hüseyin Can \\ Ege Universitesi \\ Sedef Erkunt Alak \\ Ege Universitesi \\ Ahmet Efe Köseoğlu \\ Ege Universitesi \\ Umut Şahar \\ Ege Universitesi \\ Berna Bostanbaş \\ Department of Veterinary Affairs \\ Serdar Baydarlı \\ Department of Veterinary Affairs \\ Mert Döşkaya \\ Department of Veterinary Affairs \\ Cemal ÜN ( $\nabla$ cemaluen@gmail.com ) \\ Ege Universitesi https://orcid.org/0000-0002-4248-9671
}

Research article

Keywords: CMAH gene, blood typing, mitotyping, stray cats, Turkey

Posted Date: October 5th, 2020

DOI: https://doi.org/10.21203/rs.3.rs-74796/v1

License: @ (i) This work is licensed under a Creative Commons Attribution 4.0 International License. Read Full License

Version of Record: A version of this preprint was published at BMC Genomics on April 19th, 2021. See the published version at https://doi.org/10.1186/s12864-021-07588-0. 


\section{Abstract}

Cytidine monophospho-n-acetylneuraminic acid hydroxylase ( $\mathrm{CMAH}$ ) gene associated with blood groups in cats encodes $\mathrm{CMAH}$ enzyme that converts Neu5Ac to Neu5Gc. Although variations in $C M A H$ gene of pedigree cats have been revealed, the presence/lack of them in non-pedigree stray cats is unknown. Therefore, the present study aimed to investigate the variations in CMAHgene and the quantity of Neu5Ac and Neu5Gc on erythrocytes of non-pedigree stray cats (n:12) living in İzmir, Turkey. Meanwhile, these 12 cats were typed using the mitochondrial DNA control region. Also, the frequency of blood types was determined in 76 stray cats including 12 cats that were used for CMAH and Neu5A/Neu5Gc analysis. In total, 14 SNPs were detected in $5^{\prime} \mathrm{UTR}$ as well as in exon 2, 4, 9, 10, 11 and 12 of $C M A H$ gene. Among these SNPS, $-495 \mathrm{C}>\mathrm{T}$ in 5'UTR was detected for the first time as heterozygous in type $A$ and $A B$ cats, and homozygous and heterozygous in type $B$ cats. The remaining 13 that have been detected in previous studies were also found as homozygous or heterozygous. Homozygous form (T/T) of the $-495 \mathrm{C}>\mathrm{T}$ polymorphism was found among only type $\mathrm{B}$ cats. Among the polymorphisms previously determined in the literature, homozygous form of the $-371 \mathrm{C}>\mathrm{T}$ polymorphism was found among only type $\mathrm{B}$ cats whereas heterozygous form $(A / C)$ of the $327 A>C$ polymorphism was detected in only type $A B$ cats. Both Neu5Gc and Neu5Ac were detected in type $A$ and $A B$ cats. In type $B$ cats, only Neu5Ac was detected. Among two type AB cats, the level of Neu5Ac was found higher in cat carrying heterozygous form (T/C) of $1392 \mathrm{~T}>\mathrm{C}$. Mitotypes A, A6, D, E and 1 were detected among stray cats analysed for the characterisation of $C M A H$ gene. The prevalence of type B cats (67.1\%) was higher than others. As a result, the presence of a new SNP as well as previous SNPs indicates that more variations can be found in stray cats with a more comprehensive study in the future. Also, the high prevalence of type B cats demonstrates the high risk of neonatal isoerythrolysis among stray cats living in İzmir, Turkey.

\section{Introduction}

The blood group system of cats was initially reported in the 1900's. In later years, three different blood types, called type A, B and AB, were demonstrated in cats. Genetic dominance among the three different blood types in cats has been reported $a s A>a^{a b}>b$. According to this, $A A, A a^{a b}$ and $A b$ genotypes can occur in Type A cats, $a^{a b} a^{a b}$ and $a^{a b} b$ genotypes in Type AB cats and bb genotype in Type B cats [1].

Determination of blood types in cats is important in veterinary clinical practice since blood type incompatibility causes transfusion reactions related to severe haemolytic anaemia, anaphylactic shock, and death [2]. In addition to transfusion reactions, neonatal isoerythrolysis can also occurred in cats when type $A$ or type $A B$ kittens are born from a type $B$ queen [3]. Both transfusion reactions and neonatal isoerythrolysis are caused by high anti-A antibody levels found in $B$ type cats $[4,5]$. According to data from several studies associated with blood typing in cats, type $A$ is the most prevalent blood group compared to type $B$ and $A B$. For example, it has been reported in many surveys that more than $90 \%$ of domestic cats are type $A$ [6, 7 ]. The frequency of type $B$ varies substantially from $0-59 \%$ in the distinct geographic regions. In contrast to type $A$ and $B$, the prevalence of type $A B$ is generally less than $1 \%$ worldwide [3].

The presence of different sialic acid residues on erythrocytes gives rise to different blood types in cats. Sialic acids that are expressed from echinoderms to mammals are mostly found as the terminal sugars of cell surface glycolipids and glycoproteins. There are more than 50 sialic acids derived from three main forms which are called N-acetylneuraminic acid (Neu5Ac), N-glycolylneuraminic acid (Neu5Gc) and 2-keto-3- deoxy-nonulosonic acid (KDN) [8]. Among them, the predominant sialic acids on most mammalian cells are Neu5Gc and Neu5Ac [9]. The Neu5Gc is expressed in a lot of mammals, except humans because of a deletion in the coding region of $\mathrm{CMAH}$ (cytidine monophospho-N-acetylneuraminic acid hydroxylase) gene [10]. Type $\mathrm{A}$ cats have mainly Neu5Gc and small amount of Neu5Ac, while type B cats have only Neu5Ac [11]. Type AB cats have both Neu5Gc and Neu5Ac at similar quantities [12]. It is stated that CMAH enzyme encoded by CMAH gene determines the type of sialic acid on erythrocytes by converting Neu5Ac to Neu5Gc in cats [13]. Accordingly, CMAH enzyme is active in type A cats while it is absent or nonfunctional in type B cats [1].

CMAH gene has been molecularly characterized among different cat populations and several single nucleotide polymorphisms (SNPs) (-539G $>A,-468 \mathrm{~A}$ $>\mathrm{G},-371 \mathrm{C}>\mathrm{G},-217 \mathrm{G}>\mathrm{A},-108 \mathrm{G}>\mathrm{A}, \mathrm{c} .139 \mathrm{C}>\mathrm{T}, \mathrm{c} .142 \mathrm{G}>\mathrm{A}, \mathrm{c} .179 \mathrm{G}>\mathrm{T}, \mathrm{c} .187 \mathrm{~A}>\mathrm{G}, \mathrm{c} .268 \mathrm{~T}>\mathrm{A}, \mathrm{c} .327 \mathrm{~A}>\mathrm{C}, \mathrm{c} .364 \mathrm{C}>\mathrm{T}, \mathrm{c} .374 \mathrm{C}>\mathrm{T}, \mathrm{c} .376 \mathrm{G}>\mathrm{A}, \mathrm{c} .593 \mathrm{~A}>\mathrm{C}$, c. $868 \mathrm{~A}>\mathrm{C}, \mathrm{c} .898 \mathrm{~A}>\mathrm{G}, \mathrm{c} .933 \mathrm{delA}, \mathrm{c} .993 \mathrm{~A}>\mathrm{G}, \mathrm{c} .1158 \mathrm{~T}>\mathrm{C}, \mathrm{c} .1218 \mathrm{~T}>\mathrm{C}, 1269 \mathrm{G}>\mathrm{A}, \mathrm{c} .1322 \mathrm{delT}, \mathrm{c} .1342 \mathrm{G}>\mathrm{A}, \mathrm{c} .1392 \mathrm{~T}>\mathrm{C}, \mathrm{c} .1398 \mathrm{G}>\mathrm{T}, 1458 \mathrm{~T}>\mathrm{C}, \mathrm{c} .1603 \mathrm{G}$ $>A, c .1662 G>A$ ) have been detected $[1,14,15,16]$. In addition to these SNPs, there is an 18 bp insertion in 5'UTR region. Among these variations, some have also been associated with specific blood type/types. For example, $18 \mathrm{bp}$ insertion has been reported to be specific for $\mathrm{b}$ allele found in type $\mathrm{B}$ cats as homozygous or in type $\mathrm{A}$ or $\mathrm{AB}$ cats as heterozygous [1].

There is no sufficient research about the presence/prevalence of these variations or their association with specific blood groups for stray cats of Turkey, except our previous study showing the presence of $18 \mathrm{bp}$ insertion only in two of 791 stray cats [17]. Therefore, the present study aimed to investigate the presence of these variations in non-pedigree stray cats of İzmir, Turkey and their associations with blood group and the quantity of Neu5Ac and Neu5Gc on erythrocytes. To address these purposes, routine immunological blood typing was performed for 76 stray cats and among them, blood samples of 12 cats [A (n:5); B (n:5); AB (n:2)] were used for molecular characterization of CMAHgene. Meanwhile, these 12 cats were typed by sequencing the $402 \mathrm{bp}$ region of cat mitochondrial DNA control region.

\section{Results}

\section{Prevalence of blood types}


Among 76 stray cats, 52 of them were female (68.42\%), 24 were male (31.57\%). Conventional slide test showed that 23 of them were type A (30.26\%), 51 of them were type B (67.1\%) and the remaining two were type AB $(2.63 \%)$. There was not a statistical difference associated with prevalence of blood groups between female and male cats $(P>0.05)$.

\section{Polymorphisms in CMAHgene}

CMAH gene analysis was performed using DNA samples belonging to 12 stray cats with known blood group (Table 1). During the $C M A H$ gene analysis, $5^{\prime}$ UTR region (including exon 1) as well as 14 exons (from exon 2 to exon 15 including 3'UTR region) were sequenced and analysed for SNPs. According to the results obtained, a total of 14 SNPs was detected in CMAH gene. The regions carrying SNPs were 5'UTR as well as exon 2, 4, 9, 10, 11 and 12 (Table 2). Among these SNPs, one of them caused by a cytosine-thymine substitution (-495C>T) in $5^{\prime} \mathrm{UTR}$ was detected for the first time as heterozygous in type $A$ and $A B$ cats, and homozygous and heterozygous in type B cats. The remaining 13 SNPs that have been detected in previous study were also found as homozygous or heterozygous (Table 2). Interestingly, 18 bp insertion (AACGAGCAACCGAAGCTG) reported in 5'UTR region in type B cats was not detected in any type of cats.

An association of the detected polymorphisms with cat blood types were also analysed and homozygous form ( $T / T)$ of the $-495 \mathrm{C}>\mathrm{T}$ polymorphism detected in this study was found among only in type B cats. Among the polymorphisms previously determined in the literature, homozygous form of the $-371 C>T$ polymorphism was found among only in type $B$ cats whereas heterozygous form $(A / C)$ of the c.327A $>C$ polymorphism was detected only in type $A B$ cats. In addition, only homozygous form of the $\mathrm{C} .1158 \mathrm{~T}>\mathrm{C}$ polymorphism were detected in all three blood groups.

\section{Type and amount of sialic acids in blood groups}

During this study, Neu5Ac and Neu5Gc and their levels were also investigated in cats with known blood type using the LC-MS/MS system. According to the results obtained, both Neu5Gc and Neu5Ac were detected in type A and AB cats. In type B cats, only Neu5Ac was detected. $m / z$ ratios and fragment ions detected for Neu5Ac and Neu5Gc were given in Table 3. The highest Neu5Ac level $(4.53 \mu \mathrm{g} / \mathrm{g})$ was among type B cats whereas the highest Neu5Gc level $(4.39 \mu \mathrm{g} / \mathrm{g})$ was detected among type A cats. When levels of Neu5Gc and Neu5Ac were compared within each blood group, the level of Neu5Ac was found higher in one of the two $A B$ type cats. As these two cats were compared in terms of polymorphisms, $A B$ type cat carrying homozygous form $(C / C)$ of $1392 T>C$ polymorphism in exon 11 had lower Neu5Ac than the other AB type cat carrying heterozygous form ( $T / C$ ) of $1392 T>C$ polymorphism. No association was found between the SNPs and the amounts of Neu5Gc and Neu5Ac detected in type A or B cats

\section{Mitotypes}

According to sequencing results of 402 bp mitochondrial DNA detecting the universal mitotypes, five cats (41.6\%) were found as mitotype A, three cats (25\%) as mitotype $A 6$, two cats (16.6\%) as mitotype D, one cat (8.33\%) as mitotype $E$ and the remaining cat (8.33\%) as mitotype 1 . It was detected that the cat with mitotype 1 had two polymorphisms at position 16820T>C and 16957C>T compared to reference mitotype 1 cats. Also, mitotype E cat had a polymorphism at position 63A>T compared to reference mitotype $\mathrm{E}$ cats.

\section{Discussion}

Determination of blood types in cats is important for clinical practices because of transfusion reactions and neonatal isoerythrolysis [2, 3]. Both transfusion reactions and neonatal isoerythrolysis are related to type B cats having high titer anti-A antibody $[4,5]$. In our study, the prevalence of type B cats was found higher (67.1\%) when compared to type A cats. In Turkey, the prevalence results associated with type B vary according to cat breeds. For example, in a previous study, the prevalence of type B cats was found higher than type A cats among Turkish Van cats. Also, type B prevalence (46.4\%) was found nearly equal to type A (53.6\%) in Turkish Angora cats [2]. In another study, the prevalence of type B cats was found as $35.9 \%, 32.6 \%, 30.5 \%$, and $6.1 \%$ in İstanbul, İzmit, Kırıkkale and Giresun, respectively, among non-pedigree cats [3]. These findings and our results indicate that there might be a possible risk for neonatal isoerythrolysis among pedigree cats (Turkish Van and Angora) and stray cats living in İzmir, İstanbul, İzmit and Kırıkkale provinces of Turkey.

CMAH gene that is associated with blood group system is being studying in cats for about 15 years. To date, several SNPs as well as an 18 bp insertion have been detected by sequencing $C M A H$ gene. Among these variations, some of them have also been associated with specific blood types. For example, Bighignoli et al. (2007) reported the 16 SNPs as well as an 18 insertion in $C M A H$ gene of cats and among these, $-217 \mathrm{G}>\mathrm{A},-371 \mathrm{C}>\mathrm{T}$, $\mathrm{c}$. $142 \mathrm{G}>\mathrm{A}$ (originally G139A), c.268T > A (originally T265A), c.1603G > A (originally G1600A) and 18 bp insertion were found to be specific to blood group. Accordingly, homozygous forms of these variations specific to type $B$ cats or heterozygous forms could be found in $b$ allele carrier cats such as heterozygous type $A$ and $A B$ cats. In our study, C-371T was detected in type $A, B$ and $A B$ cats as heterozygous (C/T). Moreover, homozygous form of the $-371 \mathrm{C}>\mathrm{T}$ polymorphism was found among only in type B cats. The remaining three SNPs (c.142G > A, c.268T > A, c.1603G > A) and 18 bp insertion were not detected in stray cats. These results demonstrate that there may be different variations in the $C M A H$ gene between popular cat breeds and stray cats, and some of them are more common among popular cat breeds as well as being specific to blood groups. This assertion is actually supported by a study showing the presence of c.364C > T polymorphism in only Ragdoll cat breeds with AB blood group [14].

In a different study, c.179G > T, c.187A > G, c.1218T > C and c.1662G > A polymorphisms were detected in CMAHgene of type B cats as homozygous or heterozygous. C.187A $>\mathrm{G}$ was also detected in type $A B$ cats as heterozygous [15]. In our study, C.179G $>$ T and c.1218T >C were found in type A, B and $A B$ cats as heterozygous as well as c.187A $>G$ in only type $A$ and $A B$ as heterozygous. c. $1662 G>A$ was not found in stray cats. In the following study,

Page $3 / 8$ 
additional c.374C > T, c.593A > C, c.868A > C, c.898A > G, c.933delA, c.1322delT and c.1342G > A polymorphisms were detected as homozygous or heterozygous when analysed different cat breeds including Turkish Angora cats [16]. The Turkish Angora cats that are one of the oldest cat breeds have been originated from Ankara region of Turkey which is relatively close to İzmir, our study area. Therefore, we conducted an additional comparison between Angora cats and stray cats living in İzmir for polymorphisms in CMAHgene. Accordingly, homozygous or heterozygous forms of c.139C > T, c. $179 \mathrm{G}>\mathrm{T}$, c. 187A > G and c.327A > C polymorphisms were detected as coherent in both groups. Moreover, 18 bp insertion that has not been detected in our study was found only in one type B cat among eight Turkish Angora cats analysed. These findings indicated that $139 \mathrm{C}>\mathrm{T}, \mathrm{c} .179 \mathrm{G}>\mathrm{T}$, c. $187 \mathrm{~A}>\mathrm{G}$ and c.327A > C polymorphisms were prevalent in Turkey whereas $18 \mathrm{bp}$ insertion was rare. Our previous study showing the prevalence of $18 \mathrm{bp}$ insertion as $0.25 \%(2 / 791)$ also supports this result. [17].

Polymorphisms detected in CMAHgene have also been used as a genetic marker in the determination of blood groups. For example, Tasker et al. (2014) used two SNPs (G139A and C136T) to determine blood groups and reported that serological results were $96 \%$ compatible with those of molecular methods [20]. $-495 \mathrm{C}>\mathrm{T}$ that is detected for the first time in our study and $-371 \mathrm{C}>\mathrm{T}$ were found as homozygous $(\mathrm{T} / \mathrm{T})$ in same two type $\mathrm{B}$ cats. Depending on this, it was thought that the homozygous form of these polymorphisms can be used as a marker in the detection of type $B$ cats in stray cats of İzmir. Similarly, it was thought that heterozygous form $(A / C)$ of the $327 A>C$ polymorphism detected only in type $A B$ cats can be used to detect the type $A B$ cats.

In cats, types of sialic acids related to blood groups are known. Accordingly, type A cats have Neu5Gc while type B cats have Neu5Ac. Neu5Ac can also be found at low levels in type A cats. Type AB cats have both Neu5Gc and Neu5Ac at similar levels. In our study, types of sialic acid were found as coherent with literature in blood groups. However, among two AB cats analysed, Neu5Ac was found higher (nearly 4 folds) in one. As the two cats were compared in terms of polymorphisms, only single position (1392T > C) was different. Depending on this, it was thought that the homozygous form of the polymorphism (C/C) can change Neu5Ac level in type AB cats because SNPs found in promotor, intron or exon regions of any gene have potential to change the level of protein/enzyme expressions [21].

In a previous study analysing 1394 cats from 25 distinct worldwide populations, it was reported that twelve mitotypes from $A$ to $L$ represented $83 \%$ of the cats and prevalence of A, B, C and D mitotypes were found as $66 \%$ among these cats [19]. In Turkey, mitotypes of stray cats were identified for the first time and mitotypes $A$ and $A 6$ were found as more prevalent according to identified other mitotypes including D, E and 1. Grahn et al. (2011) identified mitotypes A, A6, B, D, D5, E, F, J, OL1 and U among Turkish Angora and Van cats. Moreover, mitotype D was found as prevalent in Turkish Van $(62.5 \% ; 10 / 16)$ and Angora cats $(27 \% ; 4 / 15)[19]$. These results indicate that in Turkey, mitotype $A$ is prevalent in stray cats whereas mitotype $D$ is prevalent in pedigree cats.

\section{Conclusion}

The findings demonstrate the high risk of neonatal isoerythrolysis among stray cats because of high prevalence of type B cats. In $C M A H$ gene, identification of a new polymorphism $(-495 \mathrm{C}>\mathrm{T})$ and the presence of previously identified polymorphisms indicate that more polymorphisms can be found in stray cats with a more comprehensive study. Moreover, it was thought that the coexistence of homozygous forms of $-495 \mathrm{C}>\mathrm{T}$ and-371 $>\mathrm{T}$ polymorphisms can be used for the identification of type B cats. Also, the results show the dominancy of mitotype A in stray cats of izmir, Turkey.

\section{Methods}

\section{Collection of blood samples}

Blood samples were collected from healthy stray cats (n:76) which were brought to Veterinary Clinics in Narlıdere province of Izmir, Turkey for sterilization purposes. 1-2 $\mathrm{ml}$ of blood sample was obtained from tissue material that was removed from the anesthetized cats during sterilization, inserted into $5 \mathrm{ml}$ tubes with EDTA and kept at $+4^{\circ} \mathrm{C}$ until used. All experiments were performed under the instructions and approval of the Institutional Animal Care and Use Committee (IACUC) of Ege University for animal ethical norms (Permit number: 2010-72; 2017-008).

\section{Blood typing}

Blood typing was performed for 76 blood samples by conventional slide test as described [18]. Briefly, a serum sample belonging to type B cat as anti-A reagent and Lectin Triticum vulgaris $(1 \mathrm{mg} / \mathrm{ml})$ as anti-B reagent were used. $50 \mu \mathrm{l}$ of anti-A and anti-B reagents were individually added to a slide and both of them were gently mixed with $25 \mu \mathrm{l}$ of blood sample by a pipette. After $5 \mathrm{~min}$, blood types were detected by controlling the presence of agglutination. Among 76 blood samples, 12 of them [A (n:5); B (n:5); AB (n:2)] were also studied by a commercial immunochromatographic strip method [Alvedia rapid-test (LabTest $A+B$ ) to confirm blood type results. These confirmed samples were used for analysis of $C M A H$ gene.

\section{PCR}

DNA isolation from blood samples was conducted by PureLink Genomic DNA Mini Kit (Thermo Fisher Scientific) according to the manufacturer's instructions. During PCR, 16 different regions of $C M A H$ gene including a 5' UTR and 14 exons as well as 3'UTR were amplified using primer pairs [14-15]. PCR mixture contained $2 \mu$ template DNA, $12.5 \mu$ l Dream Taq master mix (Thermo scientific), $1 \mu \mathrm{l}$ from each of primers (10 pmol) and $8.5 \mu$ distilled water. The PCR amplifications were carried out under the following conditions: 2 min initial denaturation step at $95^{\circ} \mathrm{C}$, followed by 35 cycles of 1 min at 
$95^{\circ} \mathrm{C}, 45 \mathrm{sec}$ at $58^{\circ} \mathrm{C}$, and $45 \mathrm{sec}$ at $72^{\circ} \mathrm{C}$, and a final extension of $10 \mathrm{~min}$ at $72^{\circ} \mathrm{C}$ [1]. PCR products were run through $1 \%$ agarose gel electrophoresis and visualized.

\section{Mitotyping}

For mitotyping analysis of stray cats, a mitochondrial DNA fragment in length of $492 \mathrm{bp}$ including nucleotide variations that identify the universal mitotypes was amplified using JHmtF3-5'-GATAGTGCTTAATCGTGC-3' and JHmtR3-5'-GTCCTGTGGAACAATAGG-3' primers as described previously [19].

\section{Sequencing}

PCR products belonging to $C M A H$ gene were sequenced by $A B I 3730 X L$ and generated sequences were aligned by MEGA7.0 software to compare exons belonging to reference Felis catus CMAH gene with accession number NM_001244985.1 and to compare 5' UTR regions belonging to reference Felis catusCMAH genes with accession numbers EF127683 and EF127686. Also, PCR products belonging to mitochondrial DNA were sequenced by $\mathrm{ABI} 3730 \mathrm{XL}$ and generated sequences were aligned by MEGA7.0 software to compare with reference cat mitotypes.

\section{Phylogenetic analysis}

A phylogenetic tree among mitotypes was reconstructed by MEGA 7.0 software based on Maximum Likelihood method using Tamura-Nei Gamma distribution $(\mathrm{TN}+\mathrm{G})$ model with 500 Bootstrap replications.

\section{Preparation of the samples and LC-MS/MS analysis}

The determination of Neu5Ac and Neu5Gc in erythrocyte samples isolated from whole blood was carried out using modification of the methods reported by Hara et al. (1986) and Yeşilyurt et al (2015). Briefly, $30 \mathrm{mg}$ erythrocyte sample was incubated for 90 min at $80^{\circ} \mathrm{C}$ with $0.1 \mathrm{M}$ trifluoroacetic acid (TFA) for acid hydrolysis in order to release the sialic acids. After that, released sialic acids were derivatized with DMB (1,2-Diamino-4,5-

methylenedioxybenzene dihydrochloride) solution containing $1.55 \mathrm{mg} \mathrm{DMB}, 3.68 \mathrm{mg}$ sodium hydrosulfite and $50 \mu \mathrm{l}$ 2-mercaptoethanol prepared in 950 $\mu \mathrm{l} 0.1 \mathrm{M}$ TFA. Derivatized sialic acids were pipetted into the HPLC vial insert. The injection volume was settled to $0.3 \mu \mathrm{L}$ in the method. Commercial Neu5Ac (Sigma) and Neu5Gc (Sigma) were used as standard.

HPLC analysis was performed using an Agilent 1200 Capillary HPLC system with an ODS capillary column (Agilent ZORBAX SB-C18 1500.5 mm, 5 mm, USA). Elution was performed by isocratic mode at $20 \mu \mathrm{L} / \mathrm{min}$ using a mixture of (methanol/acetonitrile, 3:2) and water at 1:4 ratios. The column temperature was kept at $30^{\circ} \mathrm{C}$ during the analysis. All mass spectrometric measurements were performed on an HCT Ultra ion trap mass spectrometer (Bruker Daltonics, Bremen, Germany) equipped with an electrospray ionization (ESI) source in positive mode. Ion optics voltages, nebulizer gas, and dry gas flow rates, and the dry gas temperature were controlled by EsquireControl software 6.1. All mass spectra were acquired in the mass range 200-600 $\mathrm{m} / \mathrm{z}$, with a scan speed of $26,000 \mathrm{~m} / \mathrm{z}$ per second. Data analysis was carried out using Data Analysis software (v.3.4, Bruker Daltonics).

\section{Declarations}

\section{Funding}

This study was supported by a project given by The Scientific and Technological Research Council of Turkey (TÜBiTAK) (Project number: 218Z105) to C.Ü.

\section{Competing interests}

The authors declare no conflict of interest.

\section{Authors' contributions}

Conceived and designed the experiments: CÜ, HC. Performed the experiments: HC, SEA, AEK, UŞ. Analysed the data: CÜ, HC, MD. Wrote the paper: CÜ, HC. Reviewed and edited the paper: CÜ, HC, MD. All authors have read and approved the manuscript.

\section{References}

1. Bighignoli B, Niini T, Grahn RA, et al. Cytidine monophospho-N-acetylneuraminic acid hydroxylase (CMAH) mutations associated with the domestic cat AB blood group. BMC Genet. 2007;8(1), 27. https://doi.org/10.1186/1471-2156-8-27.

2. Arikan S, Duru SY, Gurkan M, Agaoglu ZT, Giger U. Blood type A and B frequencies in Turkish Van and Angora cats in Turkey. J Vet Med A Physiol Pathol Clin Med. 2003;50(6), 303-6. https://doi.org/10.1046/j.1439-0442.2003.00536.x.

3. Arikan S, Gurkan M, Ozaytekin E, Dodurka T, Giger U. Frequencies of blood type A, B and AB in non-pedigree domestic cats in Turkey. J Small Anim Pract. 2006;47(1), 10-3. https://doi.org/10.1111/j.1748-5827.2006.00005.x.

4. Knottenbelt CM, Day MJ, Cripps PJ, Mackin AJ. Measurement of titres of naturally occurring alloantibodies against feline blood group antigens in the UK. J Small Anim Pract. 1999;40(8), 365-70. https://doi.org/10.1111/j.1748-5827.1999.tb03101.x. 
5. Arıkan Ş, Gürkan M. Clinical aspects of blood transfusion in cats. Ankara Univ Vet Fak Derg. 2009;56(2), $153-7$.

6. Giger U, Bucheler J, Patterson DF. Frequency and inheritance of A and B blood types in feline breeds of the United States. J Hered. 1991;82(1), 1520. https://doi.org/10.1093/jhered/82.1.15.

7. Hohenhaus AE. Importance of blood groups and blood group antibodies in companion animals. Transfus Med Rev. 2004;18(2), 117-26. https://doi.org/10.1016/j.tmrv.2003.12.003.

8. İzzetoğlu S, Şahar U, Şener E, Deveci R. Determination of sialic acids in immune system cells (coelomocytes) of sea urchin, Paracentrotus lividus, using capillary LC-ESI-MS/MS. Fish Shellfish Immunol. 2014;36(1), 181-6. https://doi.org/10.1016/j.fsi.2013.10.029.

9. Samraj A, Läubli H, Varki N, Varki A. Involvement of a non-human sialic acid in human cancer. Front Oncol. $2014 ; 4,33$. https://doi.org/10.3389/fonc.2014.00033.

10. Irie A, Koyama S, Kozutsumi Y, Kawasaki T, Suzuki A. The Molecular Basis for the Absence of N-Glycolylneuraminic Acid in Humans. J Biol Chem. 1998;273(25), 15866-71. https://doi.org/10.1074/jbc.273.25.15866.

11. Andrews GA, Chavey PS, Smith JE, Rich L. N-glycolylneuraminic acid and N-acetylneuraminic acid define feline blood group A and B antigens. Blood. 1992;79(9), 2485-91.

12. Griot-Wenk M, Pahlsson P, Chisholm-Chait A, Spitalnik PF, Spitalnik SL, Giger U. Biochemical characterization of the feline AB blood group system. Anim Genet. 1993;24(6), 401-7. https://doi.org/10.1111/j.1365-2052.1993.tb00352.x.

13. Merbl Y, Hason A, Sethon ED, Aroch I. A survey of feline AB group blood types in Israel (2007 to 2009). Isr J Vet Med. 2011;66, 21-28.

14. Gandolfi B, Grahn RA, Gustafson NA, et al. A novel variant in CMAH is associated with blood type AB in Ragdoll cats. PloS One. 2016;11(5), e0154973. https://doi.org/10.1371/journal.pone.0154973.

15. Omi T, Nakazawa S, Udagawa C, et al. Molecular characterization of the cytidine monophosphate-N-acetylneuraminic acid hydroxylase (CMAH) gene associated with the feline AB blood group system. PloS One. 2016;11(10), e0165000. https://doi.org/10.1371/journal.pone.0165000.

16. Kehl A, Heimberger K, Langbein-Detsch I, et al. Molecular characterization of blood type A, B, and C (AB) in domestic cats and a CMAH genotyping scheme. PloS One. 2018;13(9), e0204287. https://doi.org/10.1371/journal.pone.0204287.

17. Can H, Atalay Şahar E, Döşkaya M, et al. Analysis of Cytidine Monophospho-N-Acetylneuraminic Acid Hydroxylase (CMAH) Gene Related to Neonatal Isoerythrolysis in Stray Cats of Izmir, Turkey. Kafkas Univ Vet Fak Derg. 2016;22(3), 355-9. https://doi.org/10.9775/kvfd.2015.14637.

18. Seth M, Jackson KV, Giger U. Comparison of five blood-typing methods for the feline AB blood group system. Am J Vet Res. 2011;72(2), 203-209. https://doi.org/10.2460/ajvr.72.2.203.

19. Grahn RA, Kurushima JD, Billings NC, et al. Feline non-repetitive mitochondrial DNA control region database for forensic evidence. Forensic Sci Int Genet. 2011;(1):33-42. https://doi.org/10.1016/j.fsigen.2010.01.013.

20. Tasker S, Barker EN, Day MJ, Helps CR. Feline blood genotyping versus phenotyping, and detection of non-AB blood type incompatibilities in UK cats. J Small Anim Pract. 2014;55(4), 185-9. https://doi.org/10.1111/jsap.12180.

21. Deng N, Zhou H, Fan H, Yuan Y. Single nucleotide polymorphisms and cancer susceptibility. Oncotarget. 2017;8(66), 110635-49. https://doi.org/10.18632/oncotarget.22372.

22. Hara S, Yamaguchi M, Takemori Y, Nakamura M, Ohkura Y. Highly sensitive determination of N-acetyl-and N-glycolylneuraminic acids in human serum and urine and rat serum by reversed-phase liquid chromatography with fluorescence detection. Journal of Chromatography B: Biomedical Sciences and Applications. 1986; 377, 111-119.

23. Yeşilyurt B, Şahar U, Deveci R. Determination of the type and quantity of sialic acid in the egg jelly coat of the sea urchin Paracentrotus lividus using capillary LC-ESI-MS/MS. Mol Reprod Dev. 2015;82(2), 115-122. https://doi:10.1002/mrd.22448.

\section{Tables}


Table 1

Mitotype, blood group and some phenotypic results of analysed stray cats for characterization of $\mathrm{CMAH}$ gene.

\begin{tabular}{|llll|}
\hline Sex & Color & Blood group & Mitotype \\
\hline Female & Black & AB & 1 \\
Female & Black-White & AB & A6 \\
\hline Female & Gray & A & A \\
\hline Female & Calico & A & A \\
Female & Calico & A & A6 \\
Male & Tabby (White) & A & E \\
Female & Calico & A & D \\
Female & Black-White & B & A \\
\hline Female & Tabby & B & A \\
Female & Tabby (White) & B & A6 \\
\hline Male & Black & B & D \\
Male & Tabby (White) & B & A \\
\hline
\end{tabular}

Table 2

Polymorphisms detected in the CMAHgene in stray cats of Izmir.

\begin{tabular}{|c|c|c|c|c|c|c|c|c|c|c|c|c|c|c|}
\hline Blood & $5^{\prime}$ UTR & & & & Exon 2 & & & Exon & Exon 9 & Exon 10 & & Exon 11 & & Exon \\
\hline & $\begin{array}{l}{ }^{* C-}- \\
495 T\end{array}$ & $\begin{array}{l}A- \\
468 G\end{array}$ & $\begin{array}{l}\text { C- } \\
371 T\end{array}$ & $\begin{array}{l}\text { G- } \\
108 \mathrm{~A}\end{array}$ & С139T & G179T & A187G & A327C & A993G & $\mathrm{T} 1158 \mathrm{C}$ & $\mathrm{T} 1218 \mathrm{C}$ & G1269A & T1392C & $\mathrm{T} 1458 \mathrm{C}$ \\
\hline$A B$ & CT & $A G$ & CT & $\mathrm{GA}$ & CT & GT & $A G$ & $A C$ & AA & $\mathrm{CC}$ & $\mathrm{TC}$ & GG & $\mathrm{TC}$ & $\mathrm{TC}$ \\
\hline$A B$ & CT & $A G$ & CT & GA & CT & GT & $A G$ & $A C$ & $\mathrm{AA}$ & $\mathrm{CC}$ & $\mathrm{TC}$ & GG & $\mathrm{CC}$ & $\mathrm{TC}$ \\
\hline A & CT & GG & CT & GG & CT & GT & $A G$ & $\mathrm{CC}$ & AA & $\mathrm{CC}$ & $\mathrm{TC}$ & GG & TC & $\mathrm{CC}$ \\
\hline A & $\mathrm{CT}$ & GG & CT & GG & CT & GT & $\mathrm{AA}$ & $\mathrm{CC}$ & $\mathrm{AA}$ & $\mathrm{CC}$ & TC & GG & $\mathrm{TC}$ & $\mathrm{CC}$ \\
\hline A & CT & $A G$ & CT & GG & CT & GT & $A G$ & $\mathrm{CC}$ & $\mathrm{AA}$ & $\mathrm{CC}$ & $\mathrm{TC}$ & GG & TC & $\mathrm{CC}$ \\
\hline A & $\mathrm{CT}$ & $A G$ & CT & GA & CT & GT & AA & $\mathrm{CC}$ & $\mathrm{AA}$ & $\mathrm{CC}$ & $\mathrm{TC}$ & GA & TC & $\mathrm{TC}$ \\
\hline A & CT & $A G$ & CT & $\mathrm{GA}$ & CT & GT & $A G$ & $\mathrm{CC}$ & AA & $\mathrm{CC}$ & $\mathrm{TC}$ & GG & $\mathrm{CC}$ & $\mathrm{TC}$ \\
\hline B & CT & $A G$ & CT & GG & CT & GT & AA & $\mathrm{CC}$ & $A G$ & $\mathrm{CC}$ & $\mathrm{TC}$ & GG & $\mathrm{CC}$ & $\mathrm{TC}$ \\
\hline B & $\mathrm{CT}$ & $A G$ & $\mathrm{CT}$ & GA & $\mathrm{CT}$ & GT & AA & CC & $A G$ & $\mathrm{CC}$ & $\mathrm{TC}$ & GG & $\mathrm{CC}$ & $\mathrm{TC}$ \\
\hline B & TT & GG & TT & GA & CT & GT & AA & $\mathrm{CC}$ & $A G$ & $\mathrm{CC}$ & $\mathrm{TC}$ & GG & $\mathrm{CC}$ & $\mathrm{CC}$ \\
\hline B & TT & GG & TT & GA & CT & GT & AA & CC & AA & $\mathrm{CC}$ & TC & GG & $\mathrm{CC}$ & $\mathrm{CC}$ \\
\hline B & CT & $A G$ & CT & GG & CT & GT & $\mathrm{AA}$ & $\mathrm{CC}$ & $A G$ & $\mathrm{CC}$ & TC & GG & $\mathrm{CC}$ & TC \\
\hline
\end{tabular}

Table 3

Relative retention times and characteristic ions of Neu5Ac and Neu5Gc analyzed by LCMS/MS.

\begin{tabular}{|lllll|}
\hline & & \multicolumn{3}{c|}{ Collision-induced dissociation fragments } \\
\hline Sialic acid & Retention Time & {$\left[\mathrm{M}+\mathrm{H}^{+}\right.$} & {$\left[\mathrm{M}+\mathrm{H}^{+} \mathrm{H}_{2} \mathrm{O}\right]^{+}$} & Fragments (m/z) \\
\hline Neu5Gc & 2,8 & 442 & 424 & $313-295-268-283-229$ \\
\hline Neu5Ac & 3,2 & 426 & 408 & $313-295-283-229$ \\
\hline
\end{tabular}

Figures 


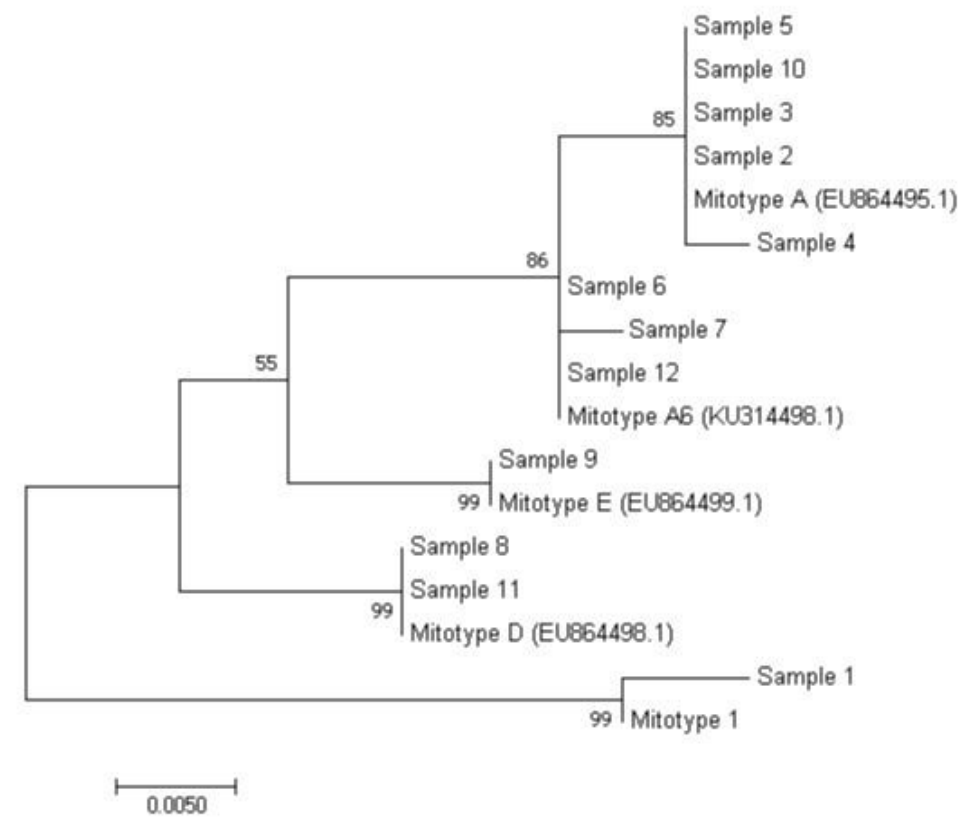

Figure 1

A phylogenetic tree of stray cats with reference cat mitotypes 